\title{
Outcomes of Evacuation Extradural Hematoma via Craniotomy under Local Anesthesia
}

\author{
Moazzam Waheed Sheikh1, Ifrah Shahnawaz', Muhammad Abdullah', Omer Kamal1, \\ Rabia Naheed ${ }^{2}$, Aisha Bushra ${ }^{3}$, Muhammad Nadeem ${ }^{3 *}$ \\ ${ }^{1}$ University College of Medicine and Dentistry, University of Lahore, Lahore, Pakistan \\ ${ }^{2}$ Fatima Memorial Hospital, Lahore, Pakistan \\ ${ }^{3}$ University at Buffalo, Buffalo, NY, USA \\ Email: moazzam_sheikh@hotmail.com, ifrah_shahnawaz@yahoo.com,drabdullahsheikh5@gmail.com, \\ omer.kama121@gmail.com,drrnaheed@gmail.com, ashasial@yahoo.com, mnadeem@buffalo.edu, „Drnadeem168@gmail.com
}

How to cite this paper: Sheikh, M.W., Shahnawaz, I., Abdullah, M., Kamal, O., Naheed, R., Bushra, A. and Nadeem, M. (2017) Outcomes of Evacuation Extradural Hematoma via Craniotomy under Local Anesthesia. Neuroscience \& Medicine, 8, 41-45.

https://doi.org/10.4236/nm.2017.83006

Received: August 9, 2017

Accepted: September 25, 2017

Published: September 28, 2017

Copyright $\odot 2017$ by authors and Scientific Research Publishing Inc. This work is licensed under the Creative Commons Attribution International License (CC BY 4.0).

http://creativecommons.org/licenses/by/4.0/

\begin{abstract}
Background: The EDH occurs due to the accumulation of bleeding between the inner table of the skull and the outer layer of the dura mater. It is said to account for $1 \%-3 \%$ of all head injured patients and $9 \%$ of those who are comatose. The only life-saving treatment of choice is evacuation of EDH via craniotomy. Methods: This was a prospective observational study, where 40 patients were in follow-up for determining the outcomes of evacuation via craniotomy. Results: Majority of the patients were young and males. The main outcome of the evacuation was favorable (recovered), but certain unfavorable outcomes were also accounted like mortality. Conclusion: The pre-surgery clinical findings like consciousness of patient were an important indicator for EDH evacuation outcome. In most of the cases, the outcome was favorable with progressive recovery.
\end{abstract}

\section{Keywords}

Evacuation, Extradural Hematoma, Mortality, Consciousness, Unfavorable Outcomes

\section{Introduction}

Head injury is a crucial health problem. The mortality due to head injury accounts for $1 \%$ of all deaths whereas it is $15 \%$ among young-aged people [1] [2]. One of the vital head injuries is Extradural hematoma (EDH). It occurs due to the accumulation of bleeding between the inner table of the skull and the outer layer of the dura mater. EDH is said to account for 1\% - 3\% [3] [4] of all head 
injured patients and $9 \%$ of those who are comatose [5]. In eighty five percent (85\%) of patients, the source of bleeding is the middle meningeal artery while in the rest, it is from middle meningeal sinus and dural sinuses [6] [7]. It is published in various reports that the deterioration of conscious level and developing focal neurological marks indicates a rapid growing (EDH) [2]. In these cases, a serious computed tomography (CT) scan will reveal biconvex hyperdense EDH. The only life-saving treatment of choice is evacuation of EDH via craniotomy [2]. The present study aims to determine the outcomes of evacuation of EDH via craniotomy under local anesthesia.

\section{Material and Methods}

This was a prospective observational study, conducted in Department of Neurology, Services Hospital, Lahore hospital. The study period was of Jan-Dec, 2016. The study exclusion criteria include all the patients with facial trauma and neck injury whereas all the patients with traumatic EDH were included in this study. The patient's medical and demographic history was noted with the main focus on the EDH. Moreover the time, place and mode of injury, details of initial management were taken into account. Another important factor; the conscious level from time of injury to admission were also noted. Later under local anesthesia the EDH injury was managed via craniotomy (surgery). Proper treatment and follow-ups were maintained for a certain time to examine the outcome of evacuation of EDH. The ethical approval was taken from the ethical committee of the hospital.

Statistical analysis: All the collected data was stored electronically \& analyzed later by using SPSS version 20. Descriptive statistics were applied to calculate mean and standard deviation. Frequency distribution and percentages were calculated for qualitative variables like gender, outcomes of evacuation. Over all a $\mathrm{P}$ values less than 0.05 was considered statistically significant.

\section{Results}

The study constitutes 40 patients with EDH traumatic injury, managed via craniotomy at xyz hospital. Out of the total, $32(80 \%)$ were males and $8(20 \%)$ were females. 5 (12.5\%) belongs to below 20, 21 (52.5\%) were with age of $21-30,10$ (25\%) were in age group of $31-40$ and $4(10 \%)$ were above 40 years of age. We observed a difference in pupil size in 20 (50\%) patients and the remaining 20 (50\%) with equal pupil and reacting to the light at time of admission. 9 (22.5\%) of the patients were with varying degrees of hemispheres. The clinical findings in patients with EDH were given in Figure 1.

All the patients went under surgery, and the EDH was evacuated through craniotomy. The outcome of the evacuation of EDH was given in Table 1.

\section{Discussion}

It is assumed that the EDH has the greatest importance among hematomas, due to its easy diagnostic and treatment [8]. The most of EDH results from blunt 


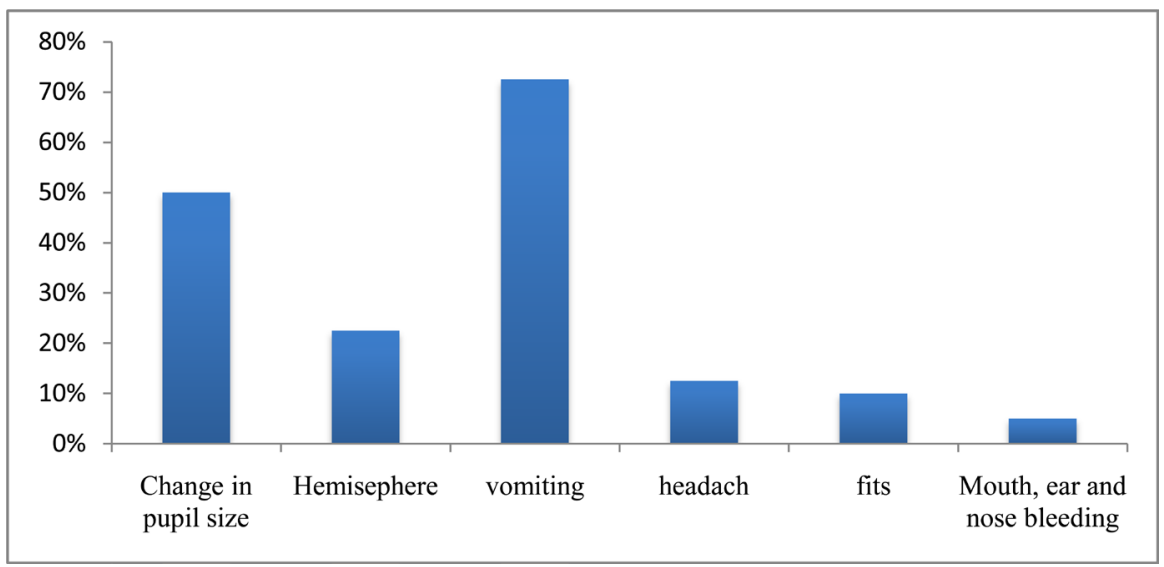

Figure 1. Clinical findings of EDH patients.

Table 1. Outcomes of evacuation of EDH via craniotomy.

\begin{tabular}{ccc}
\hline Outcome & Number of patients & Percentage \\
\hline Recovered & 36 & $90 \%$ \\
Re-operated & 3 & $8 \%$ \\
Dead & 1 & $3 \%$ \\
\hline
\end{tabular}

meninges and skull trauma. The blood accumulation between the inner table of skull and the stripped of dural membrane termed as EDH [8] [9]. Several studies indicate that this bleeding in the resulting pockets creates a hydraulic "water pressure" effect, progressively stripping the dura away from skull and thus increasing the size of EDH [10] [11]. Generally, the Skull X-ray is very good tool to assess the head injury [12]. The incidence of EDH among head injury accounts for 2\% - 3\% [13] [14] [15] [16]. Moreover, the male to female ratio of EDH is of greater importance. Obviously the males are more exposed to the social and environmental hazards, due to their occupations, they are more in number with EDH. Our findings are inline with many other published studies, showing higher proportions of male to female ration our result was within the range of many studies showing higher proportion of male to female ratios, 4:1 to 8:1 [17] [18] [19]. We also observed in our study that the most effected patients were in younger age group (21 - 30 years). Among industrial and exposed working environment a large number of employees are young. Other authors documented this factor as well [20]. We report in our observations that the prognostic factors like consciousness were the major deteriorates along with delay in surgery [21]. Others includes vomiting and headache. After the invention of the CT scan, the mortality due to $\mathrm{EDH}$ had been controlled to $12 \%$, which was before in between $29 \%$ to $33 \%$. It is foresaid that a persistent headache and vomiting are the important indications for a CT scan after head trauma [2]. The present study was conducted to examine the outcome of evacuation of EDH via craniotomy. The study findings reports that the evacuation via craniotomy was successful in major of cases, as maximum number of patients was recovered and few underwent 
re-operation. Our results were inline with other published studies where favorable functional outcome was $83.72 \%$ and the mortality was $13.95 \%$. In Khan et al. [22] study with favorable outcome was $79.2 \%$ with a mortality of $12.5 \%$. Rehman et al. [3] in their study found favorable outcome in $83.33 \%$ and mortality of $10 \%$. These are almost similar to our results. Many authors reported mortality between $10 \%$ and $20 \%$ [23] [24] [25]; others reported less than $10 \%$ mortality [26].

\section{Conclusion}

We may conclude in our study that pre surgery clinical findings like consciousness of patient were an important indicator for $\mathrm{EDH}$ evacuation outcome. In most of the cases, the outcome was favorable with progressive recovery.

\section{References}

[1] Jennet, B. and MacMillan, R. (1981) Epidemiology of Head Injury. British Medical Journal, 282, 101-104. https://doi.org/10.1136/bmj.282.6258.101

[2] Mushtaq, Rehman, L., Khaleeq, S. and Zaman, K.U. (2010) Association of Outcome of traumatic Extradural Hematoma with Glasgow Coma Scale and Hematoma Size. Annals of Pakistan Institute of Medical Sciences, 6, 133-138.

[3] Rehman, L., Khattak, A., Naseer, A. and Mushtaq (2008) Outcome of Acute Traumatic Extradural Hemorrhage. Journal of the College of Physicians and Surgeons Pakistan, 18, 759-762.

[4] Emejulu, J.K., Shokumbi, M.T. and Malomo, A.O. (2008) Determinants of Outcome in Operative Treatment of Traumatic Extradural Hematoma. West African Journal of Medicine, 27, 32-36.

[5] Bullock, M.R., Chestnut, R., Gbajar, J., Gordon, D., Hard, R., Newell, D.W., et al. (2006) Surgical Management of Acute Epidural Hematomas. Neurosurgery, 58, 52-57. https://doi.org/10.1227/01.NEU.0000210363.91172.A8

[6] Greenberg, M.S. (2001) Handbook of Neurosurgery. 5th Edition, Greenberg Graphics, New York, 660.

[7] Fishpool, S.J.C., Suren, N., Roncaroli, F. and Ellis H. (2007) Middle Meningeal Artery Haemorrhages: An Incorrect Name. Clinical Anatomy, 20, 371-375. https://doi.org/10.1002/ca.20377

[8] Agrawal, A., Agrawal, C.S., Kumar, A. and Adhikari, S. (2007) Outcome of Traumatic Extradural Haematoma Managed Surgically: Our Experience. NJOT, 6, 74-76.

[9] Price, D.D. and Wilson, S.R. (2016) Epidural Haematoma. http://emedicine.medscape.com/article/824029-media

[10] Gupta, D.K., Singh, K. and Mahapatra, A.K. (2008) Bifrontal Hyperacute Extradural Hematoma. Indian Journal of Neurotrauma, 5, 45-46.

[11] Vilela, M. and West, G.A. (2005) Traumatic Intracranial Hematomas. In: Rengachary, S.S. and Ellenbogen, R.G., Eds., Principles of Neurosurgery, No. 2, 361-362.

[12] Mendelow, A.D., Campbell, D.A., Jeffery, R.R., Miller, J.D., Hessett, C., Bryden, J. and Jannett, B. (1982) Admission after Mild Head Injury, Benefits and Costs. British Medical Journal, 285, 1530-1532. https://doi.org/10.1136/bmj.285.6354.1530

[13] Amirati, M. and Tomita, T. (1984) Posterior Fossa Epidural Hematoma during Childhood. Neurosurgery, 14, 541-544.

https://doi.org/10.1227/00006123-198405000-00002 
[14] Galbraith, S. and Smith, J. (1976) Acute Traumatic Intracranial Haematoma without Skull Fracture. The Lancet, 1, 501-503.

[15] Mazza, C., Pasqualin, A., Feriotti, G. and Da Pian, R. (1982) Traumatic Extradural Haematomas in Children: Experience with 62 Cases. Acta Neurochirurgica, 65, 67-79. https://doi.org/10.1007/BF01405443

[16] Phonprasert, C., Suwanwala, C., Hongsaprabhas, C., Prichayudh, P. and O'Charoen, S. (1980) Extradural Hematoma: Analysis of 138 Cases. The Journal of Trauma, 20, 679-683. https://doi.org/10.1097/00005373-198008000-00008

[17] Ayub, S., Ali, M. and Llyas, M. (2005) Acute Extradural Haematoma: Factors Affecting the Outcome. Journal Postgraduate Medical Institute, 19, 208-211.

[18] Mezue, W.C., Ndubuisi, C.A., Chikani, M.C., Achebe, D.S. and Ohaegbulam, S.C. (2012) Traumatic Extradural Hematoma in Enugu, Nigeria. Nigerian Journal of Surgery, 18, 80-84.

[19] Chowdhury Noman Khalid, S.M., Raihan, M.Z., Chowdhury, F.H., Ashadullah, A.T.M., Sarkar, M.H. and Hossain, S.S. (2008) Surgical Management of Traumatic Extradural Hematoma: Experience with 610 Patients and Prospective Analysis. Indian Journal of Neurotrauma, 5, 75-79.

[20] Yusuf, A.S., Odebode, T.O., Adeniran, J.O., Salaudeen, A.G., Adeleke, A.N. and Alimi, M.F. (2014) Motorcyclists Head Injury in Ilorin, Nigeria. Nigerian Journal of Basic and Clinical Sciences, 11, 80-84. https://doi.org/10.4103/0331-8540.140340

[21] Iqbal, Z., Arshad, M. and Yasin, M. (1999) Acute Traumatic Extradural Hematoma-A Study of 80 Cases. Pakistan Journal of Neurology, 5, 36-40.

[22] Khan, M.B., Riaz, M., Javed, G., Hashmi, F.A., Sanaullah, M. and Ahmed, S.I. (2013) Surgical Management of Traumatic Extradural Hematoma in Children: Experiences and Analysis from 24 Consecutively Treated Patients in a Developing Country. Surgical Neurology International, 4, 103. https://doi.org/10.4103/2152-7806.116425

[23] Kalkan, E., Cander, B., Gul, M., Girisgin, S., Karabagli, H. and Sahin, B. (2007) Prediction of Prognosis in Patients with Epidural Haematoma by a New Stereological Method. The Tohoku Journal of Experimental Medicine, 211, 235-242. https://doi.org/10.1620/tjem.211.235

[24] Weinman, D.F. and Muttukumaru, B. (1968) The Mortality from Extradural Haematoma. Australia and New Zealand Journal Surgery, 38, 104-107.

[25] Jamieson, K.G. and Yelland, J.D.N. (1968) Extradural Haematoma: Report of 167 Cases. Journal of Neurosurgery, 29, 13-23. https://doi.org/10.3171/jns.1968.29.1.0013

[26] O’Sullivan, M.G.J., Gray, W.P. and Buckley, T.F. (1990) Extradural Haematoma in the Irish Republic: An Analysis of 82 Cases with Emphasis on Delay. British Journal of Surgery, 77, 1391-1394. https://doi.org/10.1002/bjs.1800771223 
Submit or recommend next manuscript to SCIRP and we will provide best service for you:

Accepting pre-submission inquiries through Email, Facebook, LinkedIn, Twitter, etc. A wide selection of journals (inclusive of 9 subjects, more than 200 journals)

Providing 24-hour high-quality service

User-friendly online submission system

Fair and swift peer-review system

Efficient typesetting and proofreading procedure

Display of the result of downloads and visits, as well as the number of cited articles Maximum dissemination of your research work

Submit your manuscript at: http://papersubmission.scirp.org/

Or contact nm@scirp.org 